\title{
Antimicrobial Effects of 1-Monocaprylin and 1-Monocaproin Through in vitro Growth Inhibition and Molecular Docking Studies
}

\author{
${ }^{1}$ Palaniappan Maheswari and ${ }^{2}$ Kasthuri Revathi \\ ${ }^{1}$ Department of Biotechnology, Science and Humanities, Sathyabama University, \\ Jeppiaar Nagar, Rajiv Gandhi Road, Chennai - 600 119, India \\ ${ }^{2}$ Department of Zoology, Ethiraj College for Women, Egmore, Chennai- 600 008, India
}

\author{
Article history \\ Received: 16-06-2017 \\ Revised: 19-07-2017 \\ Accepted: 19-08-2017 \\ Corresponding Author: \\ Palaniappan Maheswari, \\ Department of Biotechnology, \\ Science and Humanities, \\ Sathyabama University, \\ Jeppiaar Nagar, Rajiv Gandhi \\ Road, Chennai - 600 119, India \\ Phone: 044- 25504536 \\ Email: maheswari.p1966@gmail.com
}

\begin{abstract}
: 1-monocaproin and 1-monocaprylin synthesized through a novel process by the chemical reaction of glycidol and their respective fatty acids with copper acetate as the catalyst possessed the amphiphilic property. 1monoacyl glycerols synthesized were found to exhibit antibacterial, antifungal, anti parasitic and antiviral properties. 1-monocaproin and 1monocaprylin were able to show their antibacterial effect by inhibiting the growth of the Gram negative bacteria Escherichia coli, Pseudomonas aeruginosa and Gram positive bacteria Staphylococcus aureus, Bacillus subtilis at concentrations of $100-500 \mathrm{ppm}$. The Minimal Inhibitory Concentration (MIC) of both 1-monoacyl glycerols were found to be 0.5 ppm. 1-monocaproin and 1-monocaprylin were able to show their antifungal effect by inhibiting the growth of the filamentous fungi Mucor racemosus and Rhizopus stolonifer at the concentration of $1000 \mathrm{ppm}$. Based on the molecular interaction and common binding interaction study, 1monocaproin is expected to exhibit a similar antiviral activity as that of Oseltamivir to $\mathrm{H}_{5} \mathrm{~N}_{1}$ influenza virus hemagglutinin. 1-monocaprylin and 1monocaproin synthesized using copper acetate could exhibit a broad spectrum antimicrobial effect in combination with other monoacyl glycerols or with other antimicrobial agents.
\end{abstract}

Keywords: Monoacyl Glycerols, 1-Monocaprylin, 1-Monocaproin, Antimicrobial, Anti Bacterial, Antifungal, Antiviral

\section{Introduction}

Food-borne diseases caused by the microbial contamination from bacteria, fungi, parasite and virus pose major public health problems in developed and developing countries (Altekruse et al., 1999). Food-borne infectious diseases cause serious day to day problem for the health care system and led to tremendous economic loss and hence it is important to develop the means to control the transmission from food to humans (Newell et al., 2010). This is achieved by either limiting or preventing the growth of undesirable microbial flora in food products (Dolezalkova et al., 2012). More new efficient methods for the decontamination or prevention of food contamination by these pathogens would therefore be desirable. Among the viral borne illness, avian influenza such as $\mathrm{A}\left(\mathrm{H}_{5} \mathrm{~N}_{1}\right)$ and A $\left(\mathrm{H}_{7} \mathrm{~N}_{9}\right)$ are the ones which caused serious infection in human beings. The two surface glycoprotein;
Hemagglutinin (HA) and Neuraminidase (NA) play a vital role in the attachment and release of the Influenza A virus, respectively (McNicholl and McNicholl, 2001; CDC, 2006; Lupiani and Reddy, 2009). Hemagglutinin (HA), the glycoprotein in influenza virus envelope, plays a critical role in viral binding, fusion and entry processes. Therefore, $\mathrm{HA}$ is a promising target for developing anti-influenza drugs, which block the initial entry step of viral life cycle. Recently, molecular modeling and computational chemistry based computer-aided drug design provided great help for modern drug development (Marshall, 1987). Software programs such as Auto Dock were widely used to search potential inhibitor for protein targets (Morris, et al., 2009). In this study, we employed the strategy of molecule docking to explore 1-monocaproin comparing with Oseltamivir as potential $\mathrm{H}_{5} \mathrm{~N}_{1}$ hemagglutinin inhibitors.

Monoacyl glycerols (MAGs) are gaining more attention as antimicrobial agents nowadays as they are generally 
considered as non-harmful safe agents with no adverse reactions and non- toxic to mucosa which makes them suitable for wide industrial applications. MAGs exhibit inhibitory effects against major food-borne microorganisms due to their amphiphilic and emulsifying properties (Jan et al., 2003). The precise mode of the action against microorganisms is not yet clear and postulated several hypotheses. One hypothesis is based on the amphiphilic character of MAG molecule which aids in their penetration and incorporation into cytoplasmic membrane and subsequently disrupts the cell permeability and prevents the transportation of the nutrients (Nair et al., 2004; Dufour et al., 2007). An alternative hypothesis postulates the penetration of fatty acids and dissociated in the inner cell environment, thereby increasing the intracellular acidity (Sun et al., 1998). The physicochemical and functional properties as well as antimicrobial activity of MAGs depend on the number of carbon atoms and double bonds present in the fatty acid chain (Wang and Johnson, 1997). There are many studies published recently for the monoacylglycerol with $\mathrm{C}$ 10:0 and above showing the inhibitory effects on the growth of microorganisms (Kabara et al., 1977; Razavi-Rohani and Griffiths, 1994). Hence, MAGs with C-6:0 and C-8:0 were chosen for our current study with the objectives; (1) synthesis of 1-mono caproin and 1-monocaprylin by a novel process through the catalytic addition of respective fatty acids to glycidol with copper acetate as the catalyst; (2) evaluation of the inhibition property against selected food borne bacteria and fungi through in vitro and MIC studies and (3) evaluation of the antiviral property of 1-monocaprion through the molecular interaction study and common binding interaction with crystal structure of $\mathrm{H}_{5} \mathrm{~N}_{1}$ influenza virus hemagglutinin as drug target protein along with a standard drug Oseltamivir.

\section{Materials and Methods}

\section{Details of Microorganisms}

\section{Bacterial Strains}

Salmonella typhimurium (ATCC 23765), Bacillus subtilis (ATCC 25912), E. coli (ATCC 25922), Staphylococcus aureus (ATCC 25923), Pseudomonas aeruginosa (ATCC 27853), Sterptococcus pneumonia (ATCC 34501).

\section{Fungal Strains}

Aspergillus niger (ATCC 22342), Rhizopus oryzae (ATCC 9363), Aspergillus flavus (ATCC 9643) and Leucothrix mucor (ATCC 27891).

\section{Monoacylglycerols (MAGs)}

MAGs with C-06:0 and C-08:0 were prepared as per Janis et al. (2000) published earlier but by a modified procedure using copper acetate as the catalyst. Initially, the catalysts were prepared by the reaction of $\mathrm{Cu}(\mathrm{AcO})_{2} \cdot \mathrm{H}_{2} \mathrm{O}$ with hexanoic acid and octanoic acid for the synthesis of 1- mono caproin and 1- mono caprylin respectively with toluene as the reaction medium. 1mono caproin was prepared with 0.02 mol hexanoic acid with $0.25 \mathrm{~g}$ of catalyst prepared with hexanoic acid with 0.03 mol of glycidol and the yield was $65 \%$. 1- mono caprylin was prepared with 0.01 mol octanoic acid with $0.1 \mathrm{~g}$ of catalyst prepared with octanoic acid with 0.015 mol of glycidol and the yield was $60 \%$. Products were purified for the removal of residual glycidol and to reduce the quantity of copper ions from the catalyst through column chromatography. MAGs were run through Thin Layer Chromatography (TLC) to determine their purity and confirmed by Nuclear Magnetic Resonance spectroscopy (NMR) and ensured the residual copper ions to be $<50 \mathrm{mg} \mathrm{kg}^{-1}$.

\section{Assay of Antibacterial Activities}

Bacterial strains were maintained on nutrient agar until use. The antibacterial activity of 1-monocaprion (HAP) and 1-monocaprylin (OAP) were screened using agar well diffusion method (Jahangirian et al., 2013) against the selected organism mentioned in section 2.1.1 along with control at concentrations of 100, 250 and $500 \mathrm{ppm}$ and the zone of inhibition was measured with antibiotic zone scale in $\mathrm{mm}$.

\section{Minimum Inhibitory Concentration (MIC)}

MIC of the compounds OAP and HAP were determined by agar diffusion assay method (Jahangirian et al., 2013) at four different concentrations $(0.5,1,10$ and $100 \mathrm{ppm}$ each) against $E$. coli and $S$. aureus along with control in duplicate samples.

\section{Assay of Antifungal Activities}

1-monocaprion (HAP) and 1-monocaprylin (OAP) were screened for antifungal activity (Serrano et al., 2004) against the selected organism mentioned in section 2.1.2 at the concentration of $1000 \mathrm{ppm}$ along with control with potato dextrose agar and the inhibition was represented as percentage

\section{Preparation of Molecular Structure}

To perform the molecular docking between hemagglutinin and potential inhibitors, we employed the Crystal Structure of a $\mathrm{H}_{5} \mathrm{~N}_{1}$ avian influenza virus hemagglutinin of PDB: 2KF0. The chemsketch tools were used to draw the ligands and converted in to protein data bank format for the docking using the chemical language format. 


\section{Molecular Docking}

In this study, we employed Auto Dock $4.02 \mathrm{v}$ software for the preparation of drug target protein, The polar hydrogen's were added along with kollmann charges and the respective drug target protein was saved in current mode of protein data bank. Docking was carried out with genetic algorithm mode with population size of 150 , with the maximum number of energy evaluations of 2500000, maximum numbers of generations being 27000 with 20 runs. The best run with negative binding energy was considered as best results. The interaction results were visualized using acclerys discovery studio 4.5 visualizer. Using Auto Grid program the interaction energies for the ligand, standard drug and the drug target protein were calculated and based on the above, the grid was placed in equal dimensions $50 \times 50 \times 50$ in $\mathrm{XYZ}$ dimensions with 0.4 spacing in angstroms along box is placed in $-74.536 \mathrm{X}$, 12.015 Y, 33.301 Z directions respectively. Since the active sites of hemagglutinin in $\mathrm{H}_{5} \mathrm{~N}_{1}$ were highly conserved, the docking pocket were compared with ten key amino acid residues including PHE B:63, ALA B:65, PHE B:88, LEU B:89, TRP B:92, GLY A:304, GLY A:303, CYS A:305, PRO A:306 and TYR A:308 and compared with Oseltamivir and 1-monocaproin.

\section{Results and Discussion}

\section{Anti-Bacterial Effect}

Antibacterial effects of both tested MAGs as Zone of inhibition are arrayed in Table 2 and the Zone of inhibition represented in Fig. 2. Out of the three Gram negative bacteria tested, both 1-monocaproin (HAP) and 1-monocaprylin (OAP) were effective and shown inhibition at a concentration of $100 \mathrm{ppm}$ itself for Escherichia coli and Pseudomonas aeruginosa. However, HAP and OAP were not inhibitive to Salmonella typhimurium. Out of the three Gram positive bacteria tested, both 1-monocaproin and 1monocaprylin were effective and shown inhibition at $100 \mathrm{ppm}$ itself for Staphylococcus aureus and Bacillus subtilis. However, both the monoglycerides were not inhibitive to Sterptococcus pneumonia.

There were lot published literatures to prove the inhibitory property of various MAGs against Grampositive bacteria (Kabara et al., 1972; Schlievert et al., 1992; Oh and Marshall, 1993; Branen and Davidson, 2004; Bunkova et al., 2011) and the resistant property to Gramnegative bacteria (Skrivanova et al., 2006; Kabara, 1978; Kabara, 1984). Based on detailed published studies of saturated fatty acids with chain lengths between 6 and 18 carbons, the lauric acid was found to possess more inhibitory activity against Gram-positive bacteria (Kabara et al., 1972) and MAG synthesized with caproic acid and caprylic acid in our study were found to show similar inhibitory effect.

In the earlier studies, E. coli and $P$. aeruginosa were proved to be show resistance against monocaprin even at the concentration of $1,000 \mathrm{mg} \mathrm{L}^{-1}$. However, in our studies, both 1-monocaproin and 1-monocaprylin were found to be inhibitive at $0.5 \mathrm{ppm}$ itself for these two species and to the Gram negative bacteria Staphylococcus aureus and Bacillus subtilis as shown in Fig. 3. Similar inhibitory effects were observed in monolaurin along with lactic acid on Staphylococcus aureus on meat products (Kabara, 1985). Monocaprin was found to increase the sensitivity of Bacillus cereus spores in thermal inactivation (Chaibi et al., 1998) and combined with monolaurin inhibited the growth of Listeria monocytogenes (Nair et al., 2004).

\section{Antifungal Effect}

Similarly, the MAGs were tested against fungi; Aspergillus niger, Rhizopus oryzae, Aspergillus flavus and Leucothrix mucor. Antifungal effects of both tested MAGs as \% of inhibition are expressed in Table 3. Monocaproin had shown $60 \%$ inhibition against filamentous fungi, Mucor racemosus and Rhizopus stolonifer whereas Monocaprylin had shown 80 and 65\% inhibition respectively. Both the MAGs were non inhibitory to A. niger and A flavus.

Mucormycosis, caused by Mucor species are the second prevalent mucoralean fungus surpassing the Rhizopus species (Petrikkos et al., 2012). Monoglycerides had also found to prevent or inhibit the growth of yeasts and filamentous fungi (Bergsson et al., 1998; Bunkova et al., 2010; Ruzicka et al., 2003). Monocaprin was found to be most efficient against all tested Gram-positive bacteria, yeasts and filamentous fungi except Mucor racemosus (Dolezalkova et al., 2012; Bergsson et al., 2001) whereas our compound monocaprylin showed good inhibition against Mucor racemosus and Rhizopus stolonifer. Monolaurin had shown the inhibition of spore at concentration of $0.5 \mathrm{mg}$ per $\mathrm{ml}$ for A niger and Penicillium (Rihakova et al., 2001; Mansour et al., 1996) however, the compounds tested in this study were non inhibitory.

\section{Antiviral Property}

In this study, 1-monocaproin along with Oseltamivir was employed for molecular docking with $\mathrm{H}_{5} \mathrm{~N}_{1}$ hemagglutinin as shown in Fig. 1 in which the $\mathrm{HA}_{0}$ glycoprotein of influenza virus is an integral 
membrane protein (type I transmembrane glycoprotein) with approximate dimensions of $135 \AA$ (length) $\times 35-70 \AA$ (radius). Each monomer of the HA molecule consists of a globular head domain and a stem domain. The globular domain consists of a part of $\mathrm{HA}_{1}$ only (including the receptor-binding domain and vestigial esterase domain), whereas the stem domain contains parts of both $\mathrm{HA}_{1}$ and $\mathrm{HA}_{2}$ which mediates the viral adsorption, membrane fusion, thus realizing influenza virus entry. The potential inhibitor property of 1-monocaproin was compared with Oseltamivir. The general molecular properties of the target test compounds Oseltamivir and 1-monocaproin are detailed in Table 1. The conformation variations, binding energies and inhibition constants for the molecular docking of 1-monocaproin and Oseltamivir were presented Table 4 . The minimum binding energy and other properties revealed that the 1-monocaproin and Oseltamivir could be successfully docked. The estimated free energy of 1-monocaproin was - 4.39 $\mathrm{kca} / \mathrm{mol}$ and Oseltamivir was $-7.44 \mathrm{kca} / \mathrm{mol}$. 1monocaproin showed almost $60 \%$ equivalent free energy binding ability to HA when compared to standard drug Oseltamivir. Table 5 shows the interaction of the amino acids in the $\mathrm{H}_{5} \mathrm{~N}_{1}$ HA pocket and compared with Oseltamivir and 1-monocaproin for its common interaction. Oseltamivir a standard drug showed interaction with ten amino acids with the drug target protein and 1-monocaproin showed interaction with five amino acids. The amino acid residue; PHE B: 63, TYR A: 308, CYS A: 305 showed common binding interaction in both compounds as represented in Fig. 4 and Table 5.

Table 1. Compound details

\begin{tabular}{llll}
\hline Structure & No of atoms & Molecular composition & Molecular formula \\
\hline
\end{tabular}<smiles>CCCCCC(=O)OC[C@H](O)CO</smiles>

1-Monocaproin

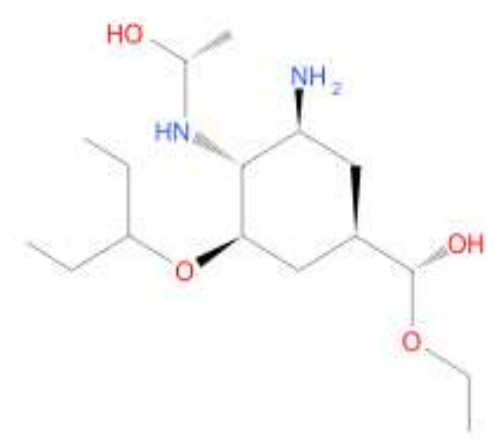

Table 2. Antibacterial effects of monoacylglycerols MAG C-06:0 and MAG C-08:0

\begin{tabular}{|c|c|c|c|c|c|c|c|}
\hline \multirow[b]{3}{*}{ Bacterial strain } & \multirow[b]{3}{*}{ Bacteria character } & \multicolumn{6}{|c|}{ Zone of Inhibition (mm) } \\
\hline & & \multicolumn{3}{|c|}{ MAG C-06:0 - HAP } & \multicolumn{3}{|c|}{ MAG C-08:0 - OAP } \\
\hline & & $500 \mathrm{ppm}$ & $250 \mathrm{ppm}$ & $100 \mathrm{ppm}$ & 500ppm & $250 \mathrm{ppm}$ & $100 \mathrm{ppm}$ \\
\hline Escherichia coli & Gram-negative & 10 & 11 & 12 & 8 & 10 & 11 \\
\hline Salmonella typhimurium & Gram-negative & NI & NI & NI & NI & NI & NI \\
\hline Pseudomonas aeruginosa & Gram-negative & 10 & 10.75 & 11 & 10 & 11.75 & 12.45 \\
\hline Staphylococcus aureus & Gram-positive & 8 & 9 & 9 & 10 & 10.25 & 11 \\
\hline Bacillus subtilis & Gram-positive & 8 & 8.5 & 9 & 10 & 10.5 & 10.5 \\
\hline Sterptococcus pneumonia & Gram-positive & NI & NI & NI & NI & NI & NI \\
\hline
\end{tabular}

Values represent the average of duplicate samples; NI -Not Inhibiting; HAP- Monocaproin; OAP - Monocaprylin 
Table 3. Zone of Inhibition of monoacylglycerols MAG C-06:0 and MAG C-08:0 against filamentous fungi

\begin{tabular}{llll}
\hline Microbial strain & & \% of inhibition & \\
\hline Aspergillus flavus & Fungal character & MAG C-06:0 - HAP & MAG C-08:0 - OAP \\
Aspergillus niger & Filamentous fungi & NI & NI \\
Mucor racemosus & Filamentous fungi & NI & NI \\
Rhizopus stolonifer & Filamentous fungi & 60 & 80 \\
\hline Valamentous fungi & Filament & 60 & 65 \\
\hline
\end{tabular}

Values represent the average of duplicate samples; HAP- Monocaproin; OAP - Monocaprylin; NI - Not Inhibiting

Table 4. The Energies of binding between $\mathrm{H}_{5} \mathrm{~N}_{1} \mathrm{HA}$ and the targeted compounds 1-monocaproin and Oseltamivir

\begin{tabular}{lll}
\hline Parameters & $1-$ monocaproin (Drug candidate) & Standard oseltamivir \\
\hline Estimated inhibition constant, Ki & $98.61 \mu \mathrm{m}$ & $3.52 \mu \mathrm{m}$ \\
Estimated free energy of binding & $-4.39 \mathrm{kca} / \mathrm{mol}$ & $-7.44 \mathrm{kca} / \mathrm{mol}$ \\
Final intermolecular energy & $-6.77 \mathrm{kca} / \mathrm{mol}$ & $-9.83 \mathrm{kca} / \mathrm{mol}$ \\
vdW + Hbond + desolv energy & $-6.61 \mathrm{kcc} / \mathrm{mol}$ & $-9.78 \mathrm{kcc} / \mathrm{mol}$ \\
Electrostatic energy & $-0.17 \mathrm{kca} / \mathrm{mol}$ & $-0.04 \mathrm{kca} / \mathrm{mol}$ \\
Final total internal energy & $-0.57 \mathrm{kca} / \mathrm{mol}$ & $-1.11 \mathrm{kca} / \mathrm{mol}$ \\
Torsional free energy & $+2.39 \mathrm{kca} / \mathrm{mol}$ & $+2.39 \mathrm{kca} / \mathrm{mol}$ \\
Unbound system's energy & $-0.57 \mathrm{kca} / \mathrm{mol}$ & $-1.11 \mathrm{kca} / \mathrm{mol}$ \\
\hline
\end{tabular}

Table 5. Binding energy of the ligands to the active site/binding site hemagglutinin $\left(\mathrm{H}_{5} \mathrm{~N}_{1}\right)$ drug target of the of avian influenza

\begin{tabular}{lll}
\hline Hemagglutinin $\left(\mathrm{H}_{5} \mathrm{~N}_{1}\right)$ drug target & Aminoacid binding & distance in $\AA$ \\
\hline 1-Monocaproin & PHE B:63 & 1.97 \\
& HIS A:295 & 4.41 \\
& TYR A:308 & 5.26 \\
& THR A:301 & 2.48 \\
Oseltamivir & CYS A:305 & $3.51,2.18$ \\
& PHE B:63 & $4.21,2.16,2.18$ \\
& ALA B:65 & 3.55 \\
& PHE B:88 & 4.79 \\
& LEU B:89 & 4.85 \\
& TRP B:92 & 2.76 \\
& GLY A:304 & 2.84 \\
& GLY A:303 & 2.88 \\
& CYS A:305 & 2.03 \\
& PRO A:306 & 2.73 \\
\hline
\end{tabular}

Note: $\mathrm{A}$ and $\mathrm{B}$ are chain in proteins

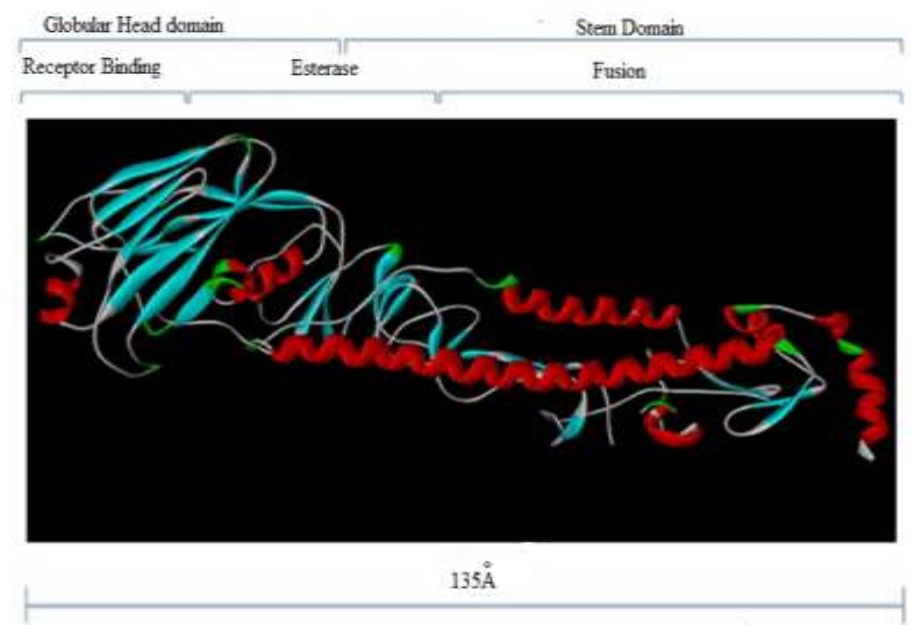

Fig. 1. Structural features of the influenza virus hemagglutinin. The picture shows $\alpha$-helices and $\beta$-sheets of $\mathrm{HA}_{0}$ folded into a compact monomer; an unfolded polypeptide chain of $\mathrm{H}_{5} \mathrm{~N}_{1}$ virus, which is composed of Heamagglutinin (HA) containing 3 different regions: (i) fusion (comprised of the $N$ - and $C$-terminal regions of HA1 ( $\mathrm{F}^{\prime}$ sub-domain) and $\mathrm{HA}_{2}$ (F sub-domain), which are located in the stem domain, a main structure responsible for membrane fusion machinery), (ii) esterase (comprised of two sub-domains between Fusion and receptor binding regions, which are located in the middle of folded HA and (iii) receptor binding (almost in the middle of $\mathrm{HA}_{1}$ of unfolded $\mathrm{HA}$ and at the top of folded HA regions) 

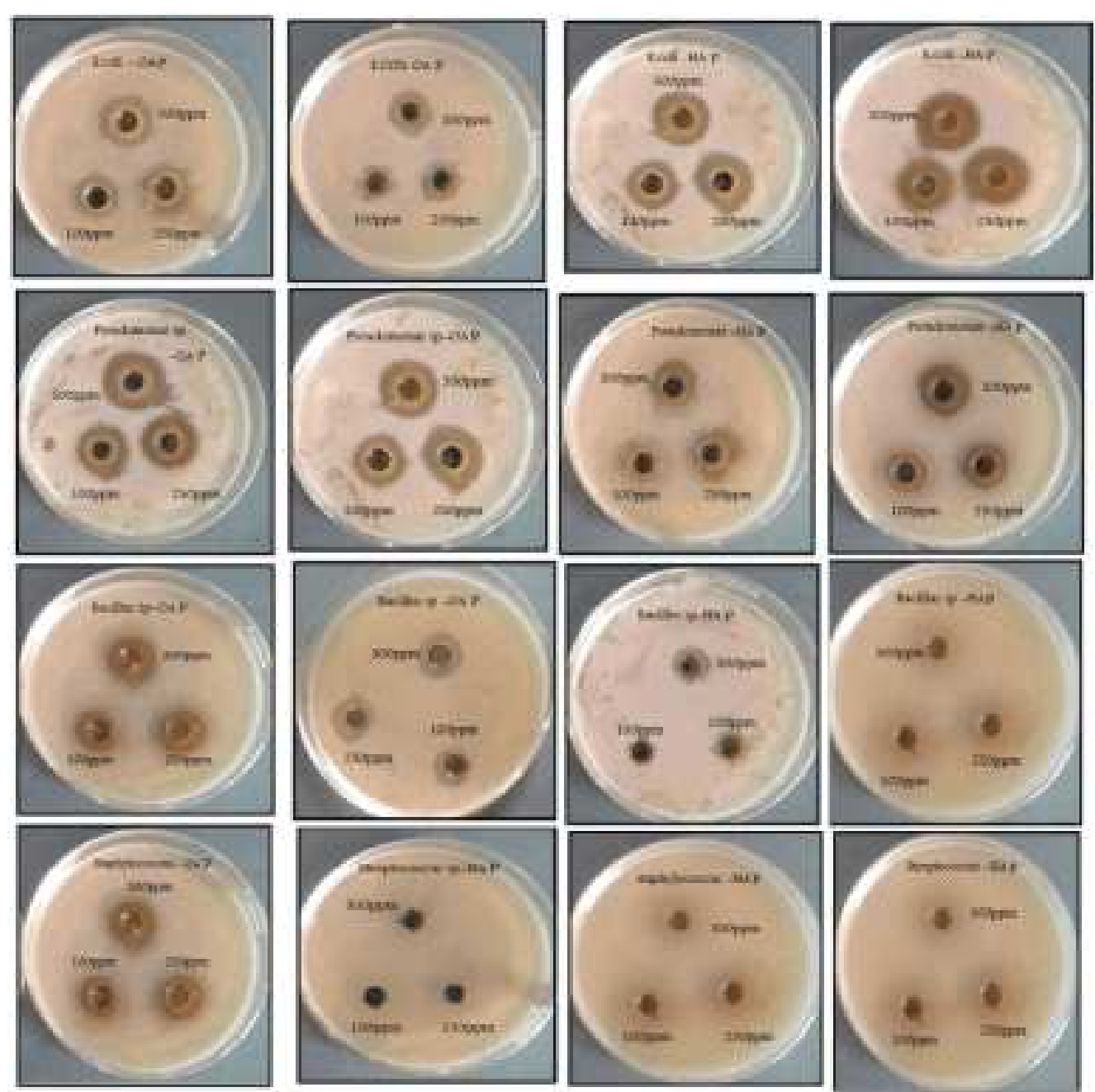

Fig. 2. Zone of inhibition. 1-monocaproin (HAP) and 1-monocaprylin (OAP) showing anti bacterial effect at a minimal dosage of 100 ppm against Gram negative bacteria Escherichia coli and Pseudomonas aeruginosa and gram positive bacteria Staphylococcus aureus and Bacillus subtilis
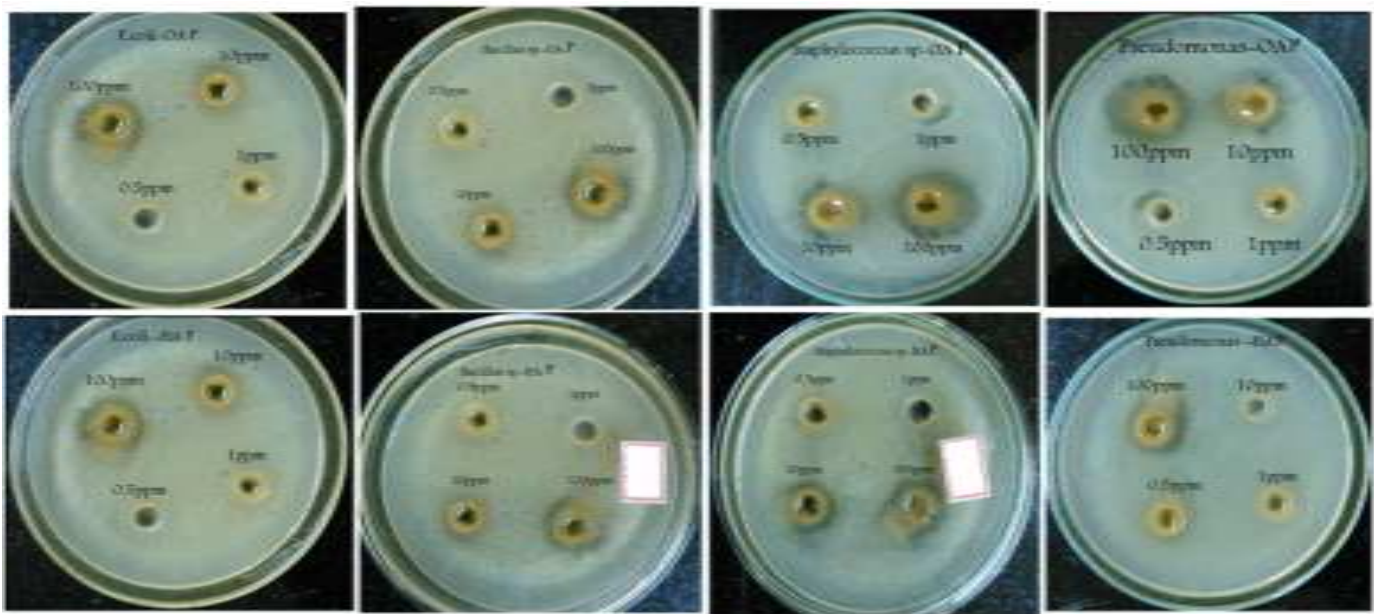

Fig. 3. Minimum Inhibitory effect 1-monocaproin (HAP) and 1-monocaprylin (OAP) showing MIC at the concentration of 0.5 ppm for Staphylococcus aureus and Bacillus subtilis 


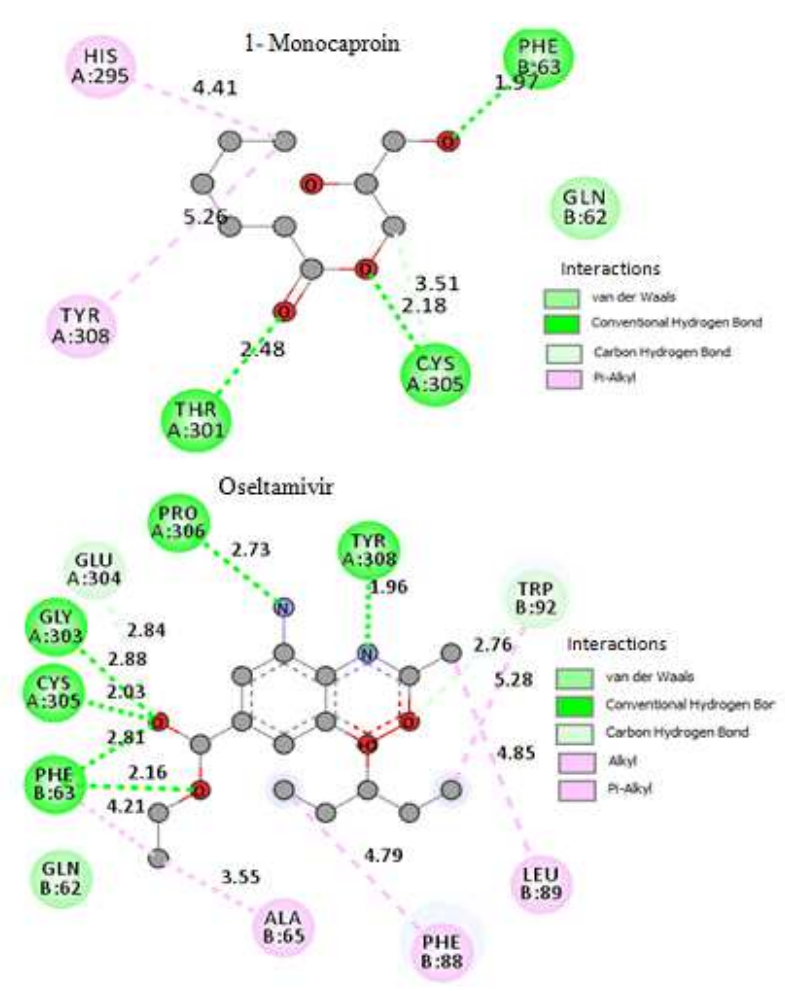

Fig. 4. Active site amino acid with 1-monocaproin and Oseltamivir; Binding interaction

Nowadays, two classes of anti-influenza drugs, $\mathrm{M}_{2}$ ion channel inhibitors and neuraminidase inhibitors respectively, are used for prophylaxis and treatment of influenza virus infection. Hemagglutinin (HA), the glycoprotein in influenza virus envelope, plays a critical role in viral binding, fusion and entry processes. Therefore, HA is a promising target for developing antiinfluenza drugs, which block the initial entry step of viral life cycle (Shen et al., 2013). Generally, AIV including $\mathrm{H}_{5} \mathrm{~N}_{1}$ are sensitive to Oseltamivir and a small number of $\mathrm{H}_{5} \mathrm{~N}_{1}$ strains isolated from avian and human origin have been reported to exhibit resistance to Oseltamivir. Oral application of Oseltamivir via drinking water reduced the morbidity, mortality, virus excretion and chicken-to-chicken transmission in HPAIV $\mathrm{H}_{5} \mathrm{~N}_{2}$ experimentally infected chickens (WHO, 2012). Oseltamivir was non-toxic for chicken embryos and prevented the replication of an HPAIV H7N1 in inoculated eggs (Allen et al., 2006). Since Oseltamivir had shown strong interaction with the amino acids in the active site of Hemagglutinin of $\mathrm{H}_{5} \mathrm{~N}_{1}$ virus, it is considered to block the HA-mediated viral entry by interfering with the receptor binding thereby cause the cleavage of $\mathrm{HA}_{0}$, followed by acidic $\mathrm{pH}$-mediated fusogenic rearrangement of $\mathrm{HA}_{2}$ and thereby prevent the viral entry related factors. Since $60 \%$ similarities were found in the estimated free energy and common binding interaction with 3 amino acids between Oseltamivir and 1-monocaproin, 1-monocaproin is also expected to exhibit similar inhibiting effect against $\mathrm{H}_{5} \mathrm{~N}_{1}$ hemagglutinin. Hence based on the molecular interaction study and common binding interaction of the compounds, the isolated compound 1monocaproin will also behave like Oseltamivir. The previous study with homology modeling and docking with 3D structure of the S-Adenosylmethionine synthase a key enzyme in E. Maximum with 1monocaproin revealed that the synthesized 1monocaproin was found to possess anti parasite effect as well (Maheswari and Revathi, 2016).

\section{Conclusion}

At present, the food industries employ MAGs merely as emulsifying agents or stabilizers and it is the right time that MAGs are considered most significantly as antimicrobial agents. Since no single MAGs exhibited a broad spectrum antimicrobial effect, it can be concluded that a combination of MAGs synthesized with $\mathrm{C}: 06: 0$ to $\mathrm{C}: 12: 0$ carbon containing fatty acids may be considered as generalpurpose antimicrobials and preservatives as they exhibit their inhibitory activity at very low concentration itself and hence cost effective as well. As 1-monocaproin docking with $\mathrm{H}_{5} \mathrm{~N}_{1}$ Hemagglutinin of avian influenza virus showed $\mathrm{Ki}$ value of $98.61 \mu \mathrm{m}$ is lesser than standard, 1-monocaproin could be a potent antiviral agent against $\mathrm{AV} \mathrm{H}_{5} \mathrm{~N}_{1}$ and perhaps 
could provide the similar effect as that of Oseltamivir at higher dose. Hence the compounds synthesized for this study; 1-monocaproin and 1-monocaprylin remains promising for numerous applications and need to be explored further.

\section{Acknowledgement}

We thank Bioneemtec India Private Limited, located at Golden Jubilee Biotech Park for Women Society, Chennai for their facility and support.

\section{Author's Contributions}

Palaniappan Maheswari: Designed the research plan, participated in all experiments, coordinated the data-analysis and writing the manuscript.

Kasthuri Revathi: Contributed in the experimental design, organised for the study and reviewed the manuscript.

\section{Ethics}

The authors declare that they have no competing interests in this work.

\section{References}

Altekruse, S.F., N.J. Stern, P.I. Fields and D.L. Swerdlow, 1999. Campylobacter jejuni--an emerging foodborne pathogen. Emerging Infect. Dis., 5: 28-35. DOI: 10.3201/eid0501.990104

Bergsson, G., J. Arnfinnsson O. Steingrimsson and H. Thormar, 2001. Killing of gram-positive cocci by fatty acids and monoglycerides. APMIS, 109: 670-678. DOI: 10.1034/j.1600-0463.2001.d01-131.x

Bergsson, G., J. Arnfinnsson, S.M. Karlsson, O. Steingrimsson and H. Thormar, 1998. In vitro inactivation of Chlamydia trachomatis by fatty acids and monoglycerides. Antimicrobial Agents Chemotherapy, 42: 2290-2294.

Branen, J. and P.M. Davidson, 2004. Enhancement of nisin, lysozyme and monolaurin antimicrobial activities by ethylenediaminetetraacetic acid and lactoferrin. Int. J. Food Microbio., 90: 63-74. DOI: $10.1016 / \mathrm{S} 0168-1605(03) 00172-7$

Bunkova, L., F. Bunka R. Janis J. Krejci and I. Dolezalkov, et al., 2011. Comparison of antibacterial effect of seven 1-monoglycerides on foodborne pathogens or spoilage bacteria. Acta Vet., 80: 29-39. DOI: $10.2754 /$ avb201180010029

Bunkova, L., J. Krejci R. Janis V. Kasparkova and P. Vltavska et al., 2010. Influence of monoacylglycerols on growth inhibition of micromycetes in vitro and on bread. Eur. J. Lipid Sci Tech., 112: 173-179. DOI: 10.1002/ejlt.200900070
CDC, 2006. Centers for disease control and prevention: High levels of adamantane resistance among influenza A $\left(\mathrm{H}_{3} \mathrm{~N}_{2}\right)$ viruses and interim guidelines for use of antiviral agents-United States, 2005-06 influenza season. MMWR Morb. Mortal, Wkly, 55: 44-46.

Chaibi, A., L.H. Ababouch M.R.Ghouila and F.F. Busta, 1998. Effect of monoglycerides on the thermal inactivation kinetics of Bacillus cereus F4165/75 spores. Food Microbiol., 15: 527-537. DOI: $10.1006 /$ fmic. 1998.0191

Dolezalkova, I., Z. Macalik, A. Butkovicova, R. Janis and L. Bunkova, 2012. Monoacylglycerols as fruit juices preservatives. Czech J. Food Sci., 30: 567-572.

Dufour, M., J.M. Manson, P.J. Bremer, J.P. Dufour and G.M. Cook et al., 2007. Characterization of monolaurin resistance in Enterococcus faecalis. Applied Environ. Microbiol., 73: 5507-5515.

Jahangirian, H., M.J. Haron, M.H.S. Ismail, R. Rafiee-Moghaddam and L. Afsah-Hejri et al., 2013. Well diffusion method for evaluation of antibacterial activity of copper phenyl fatty hydroxamate synthesized from canola and palm kernel oils. Digest J. Nanomaterials Biostructures, 8: 1263-1270.

Jan, R., K. Velclova, R. Janis and J. Krejci, 2003. Antimicrobial effects of 1-monoacylglycerols prepared by catalytic reaction of glycidol with fatty acids. Eur. Food Res. Technol., 217: 329-331. DOI: $10.1002 /$ jcc. 21256

Janis, R., J. Krejci and A. Klasek, 2000. Preparation of 1-monoacyIgIyceroIs from gIycidoI and fatty acids catalyzed by the chromium (III)-fatty acid system. Eur. J. Lipid Sci. Technol., 102: 351-354.

Kabara, J.J., 1978. Structure-function relationships of surfactants as antimicrobial agents. J. Society Cosmetic Chem., 29: 733-741.

Kabara, J.J., 1985. Inhibition of Staphylococcus Aureus in a Model Sausage System by Monoglycerides. In: The Pharmacological Effect of Lipids II, Kabara, J.J. (Ed.), Amer Oil Chemists Society, ISBN-10: 0935315020, pp: 74-76.

Kabara, J.J., D.M. Swieczkowski A.J. Conley and J.P. Truant, 1972. Fatty acids and derivatives as antimicrobial agents. Antimicrob. Agents Chemother., 2: 23-28. DOI: 10.1128/AAC.2.1.23

Kabara, J.J., R. Vrable and M.L.K Jie, 1977. Antimicrobial lipids: Natural and synthetic fatty acids and monoglycerides. Lipids, 12: 753-759.

Kabara, J.J., 1984. Antimicrobial agents derived from fatty acids. J. Am. Oil Chem. Soc., 61: 397-403. DOI: $10.1007 / \mathrm{BF} 02678802$

Lupiani, B. and S.M. Reddy, 2009. The history of avian influenza. Comp. Immunol. Microbiol. Inf. Dis., 32: 311-23. DOI: 10.1016/j.cimid.2008.01.004

Mansour, N., A.E. Yousef and J.G. Kim, 1996. Inhibition of surface growth of toxigenic and nontoxigenic aspergilli and penicillia by eugenol, isoeugenol and monolaurin. J. Food Safety, 16: 219-229. DOI: $10.1111 /$ j.1745-4565.1996.tb00162.x 
Marshall, G.R., 1987. Computer-aided drug design. Ann. Rev. Pharmacol. Toxicol., 27: 193-213. DOI: 10.1146/annurev.pa.27.040187.001205

McNicholl, I.R. and J.J. McNicholl, 2001. Neuraminidase inhibitors: Zanamivir and oseltamivir. Ann. Pharmacother., 35: 57-70. DOI: 10.1345/aph.10118

Morris, G.M., H. Ruth, W. Lindstrom, M.F. Sanner and R.K. Belew et al., 2009. AutoDock4 and AutoDockTools4: Automated docking with selective receptor flexibility. J. Comput. Chem., 30: 2785-2791. DOI: $10.1002 /$ jcc. 21256

Nair, M.K.M., P. Vasudevan, T. Hoagland and K. Venkitanarayanan, 2004. Inactivation of Escherichia coli O157: $\mathrm{H}_{7}$ and listeria monocytogenes in milk by caprylic acid and monocaprylin. Food Microbiol., 21: 611-616. DOI: 10.1016/j.fm.2004.01.003

Newell, D.G., M. Koopmans, L. Verhoef, E. Duizer and A. Aidara-Kane et al., 2010. Food- borne diseases the challenges of 20 years ago still persist while new ones continue to emerge. Int. J. Food Microbiol., 139: S3- S15. DOI: 10.1016/j.ijfoodmicro.2010

Oh, D.H. and D.L. Marshall, 1993. Antimicrobial activity of ethanol, glycerol monolaurate or lactic acid against Listeria monocytogenes. Int. J. Food Microbio., 20: 239-246. DOI: 10.1016/0168-1605(93)90168-G

Petrikkos, G., A. Skiada O. Lortholary E. Roilides and T.J. Walsh et al., 2012. Epidemiology and clinical manifestations of mucormycosis. Clin. Infect. Dis., 54: S23-S34. DOI: 10.1093/cid/cir866

Razavi-Rohani, S.M. and M.W. Griffiths, 1994. The effect of mono and polyglycerol laurate on spoilage and pathogenic bacteria associated with foods. J. Food Safety., 14: 131-151. DOI: $10.1111 / \mathrm{j} .1745-4565.1994 . t b 00590$.

Rihakova, Z., V. Filip and J. Smidrkal, 2001. Antifungal effectiveness of glycerol esters with lauric acid and its dependency on their purity. Adv. Food Sci., 23: 57-62.

Ruzicka, J., K. Velclova, R. Janis and J. Krejci, 2003. Antimicrobial effects of 1-monoacylglycerols prepared by catalytic reaction of glycidol with fatty acids. Eur. J. Lipid Sci. Tech., 2003; 217: 329-331.
Schlievert, P.M., J. Deringer, M.H. Kim S.J. Projan and R.P. Novick, 1992. Effect of glycerol monolaurate on bacterial growth and toxin production. Antimicrob Agents Ch., 30: 626-631. DOI: 10.1128/AAC.36.3.626

Serrano, M.C., M. Ramirez, D. Morilla, A. Valverde and M. Chávez et al., 2004. A comparative study of the disc diffusion method with the broth microdilution and Etest methods for voriconazole susceptibility testing of Aspergillus spp. J. Antimicrob Chemother., 53: 739-742. DOI: 10.1093/jac/dkh172

Skrivanova, E., M. Marounek, V. Benda and P. Brezina, 2006. Susceptibility of Escherichia coli, Salmonella sp. and Clostridium perfringens to organic acids and monolaurin. Vet. Med., 51: 81-88.

Sun, C.Q., C.J. O'Connor, S.J. Turner, G.D. Lewis and R.A. Stanley et al., 1998. The effect of $\mathrm{pH}$ on the inhibition of bacterial growth by physiological concentrations of butyric acid: Implications for neonates fed on suckled milk. Chemi-Biol. Interact., 113: 117-131. DOI: 10.1016/S0009-2797(98)00025-8

Wang, L.L. and E.A. Johnson, 1997. Inhibition of listeria monocytogenes by fatty acids and monoglycerides. J. Food Prot., 60: 131-138.

Shen, X., X. Zhang and S. Liu, 2013. Novel hemagglutininbased influenza virus inhibitors. J. Thorac. Dis., 5: S149-S159.

WHO, 2012. World Health Organization: Use of antiviral drugs in poultry, a threat to their effectiveness for the treatment of human avian influenza. World Health Organization.

Allen, U.D., F.Y. Aoki and H.G. Stiver, 2006. The use of antiviral drugs for influenza: Recommended guidelines for practitioners. Can. J. Infect Dis. Med. Microbiol., 17: 273-284.

Maheswari, P. and K. Revathi, 2016. Homology modeling of S-adenosylmethionine synthase present in E. maximum as a drug target and its docking with 1monocaproin. JCPR, 8: 1118-24. 